\title{
Sequencing and phylogenetic characterisation of a fatal Crimean - Congo haemorrhagic fever case imported into the United Kingdom, October 2012
}

B Atkinson ${ }^{1}$, J Latham ${ }^{1}$, J Chamberlain ${ }^{1}$, C Logue ${ }^{1}$, L O’Donoghue ${ }^{1}$, J Osborne ${ }^{1}$, G Carson $^{1}$, T Brooks ${ }^{1}$, M Carroll $^{1}$, M Jacobs $^{2}$, S

Hopkins ${ }^{2}$, R Hewson (Roger.Hewson@hpa.org.uk) ${ }^{1}$

1. Microbiology Services Division, Health Protection Agency, Porton Down, Salisbury, United Kingdom

2. High Security Infectious Disease Unit, Royal Free Hospital, London, United Kingdom

A patient with fever, and haemorrhagic symptoms was admitted to a hospital in Glasgow on 2 October 2012. Since he had returned from Afghanistan, serum samples were sent for diagnosis at the Rare and Imported Pathogens Laboratory, where a real-time reverse transcriptase-PCR diagnosis of Crimean - Congo haemorrhagic fever was made within 3 hrs after receipt of the sample. Hereafter the patient was transferred to a high-security infectious diseases unit in London but died on 6 October.

\section{Case report}

A 38 year-old male resident of the United Kingdom (UK), returned to Glasgow on Tuesday 2 October 2012 after having visited Afghanistan. He arrived in Glasgow from Kabul, Afghanistan via Dubai and was symptomatic from approximately 28 September with fever, diarrhoea, abdominal pain, haemoptysis and haematemesis. He attended the Emergency Department of a local hospital within three hours of his arrival from where he was transferred to a negative pressure room at Gartnavel General hospital, Glasgow. The patient had alanine aminotransferase (ALT) levels of $>1,000$ IU/L (norm: $20-50 \mathrm{IU} / \mathrm{L}$ ) and a platelet count of $6 \times 10^{9} / \mathrm{L}$ (norm: 150-400x109/L). No other indices were available. On 3 October 2012, a serum sample was couriered to the Health Protection Agency's (HPA) Microbiology Services Division (MSD), Porton Down which tested PCR-positive for Crimean - Congo haemorrhagic fever (CCHF) in an assay developed in-house following collaborative work between HPA and Central Asian colleagues. The patient was given intravenous ribavirin and stabilised overnight before being transferred under high security precautions by air to the highsecurity infectious diseases unit at the Royal Free Hospital, London on 5 October in a specialist isolation facility with the support of the Scottish Ambulance Service and the Royal Air Force (RAF). The patient died on 6 October, despite intensive treatment.

\section{Laboratory investigations}

The patient's serum sample arrived at MSD on the night of 3 October and was processed for RNA extraction immediately using an EZ1 DSP Virus kit (Qiagen) for PCR by on-call staff. Given the patient's travel history and symptoms, serum RNA was tested using an in-house CCHF real-time reverse transcriptase (RT) $P C R$ assay [1]. This assay enabled rapid and specific detection of the CCHF small genomic segment (S segment) within one hour of extraction, permitting prompt communication of diagnosis of CCHF to clinicians. The viral load in this sample was estimated to be $6.0 \times 10^{7}$ copies (Segment)/mL. Additional characterisation of the virus was carried out by standard Sanger sequencing on a 3130xl sequencer (Life Technologies) using our CCHF primer collection. This provided full length sequence of the $\mathrm{S}$ segment within $48 \mathrm{hrs}$, contributing additional information on the CCHF virus infection. Sequence characterisation facilitated a detailed phylogenetic analysis with other CCHF viruses, placing the $\mathrm{S}$ segment within the Asia 1 group as was expected given the geographic location of the infection (Figure). The sequence was released to Genbank on 8 October (GenBank accession number: JX908640).

\section{Control measures}

In the absence of a timely diagnosis, CCHF virus has a propensity for nosocomial transmission [2, 3, 4], thus rapid diagnosis is important for clinicians so that prompt implementation of barrier nursing techniques and patient isolation can be established. Once confirmatory diagnosis of CCHF was made in this case, the decision to transfer the patient to the high security infectious disease unit at the Royal Free was taken in line with national protocols [5] for the management of viral haemorrhagic fever cases in the UK. The patient was transported to the hospital in London via the ambulance service and the RAF's air transport isolator [6]. Confirmatory diagnosis also initiated the follow-up 


\section{FIGURE}

Maximum likelihood phylogenetic tree compiled from full length S segments of Crimean-Congo haemorrhagic fever (CCHF) virus

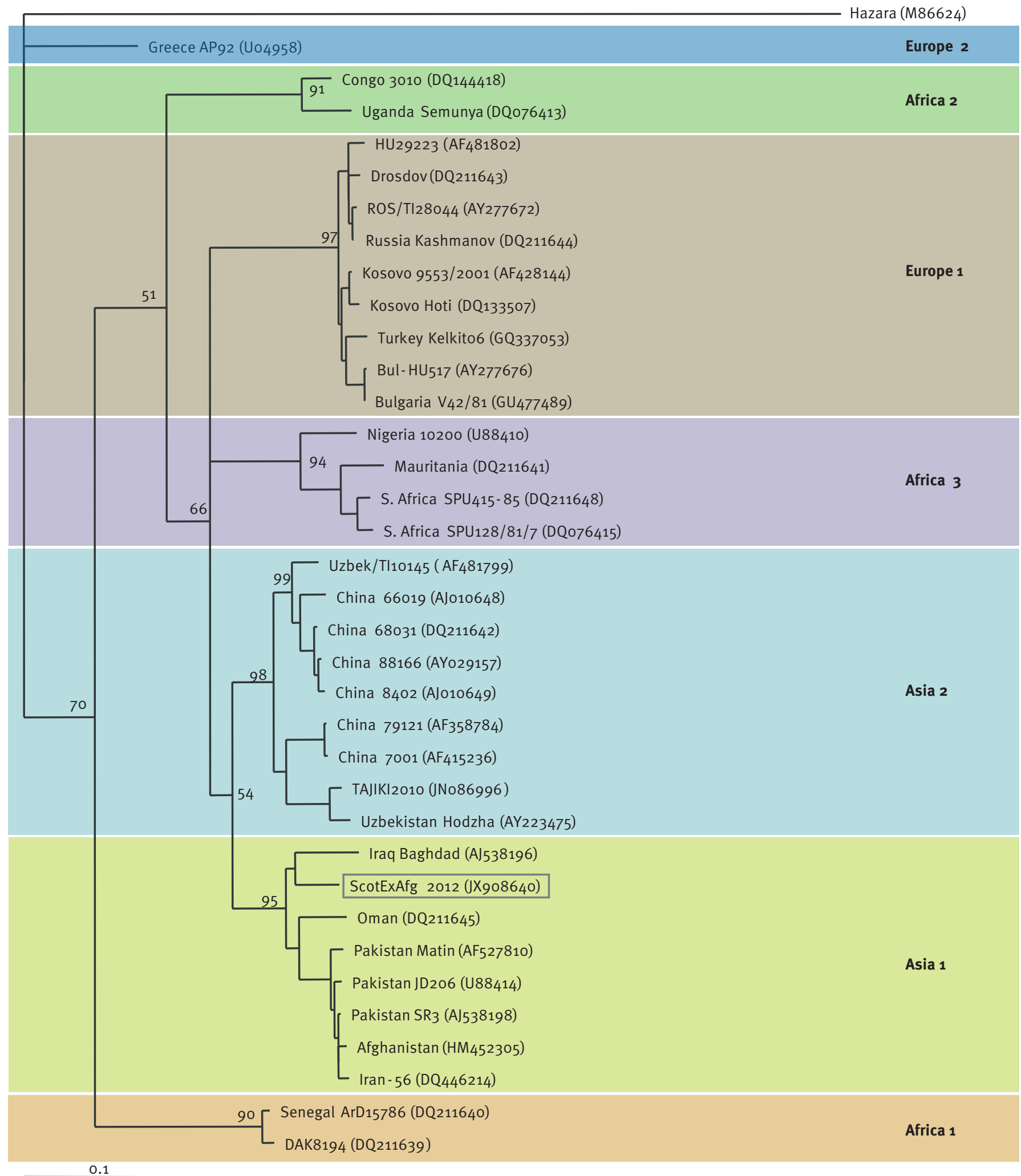

The tree was constructed to determine the similarity and origin of the strain affecting the patient. It is rooted with the closely related Hazara virus. The genomic S segment of SCT ex Afg (GenBank accession number: JX908640) clusters with the Asia 1 group, showing close similarity to other strains from the Middle East. 
of potential patient contacts by the National Health Service (NHS), Greater Glasgow and Clyde, together with colleagues from Health Protection Scotland. All potential contacts including the airline crew, cleaning staff and passengers who had sat closest to the patient were interviewed. Individuals who had direct contact with the patient were risk-assessed and, as a precaution, three people that had contact with tissue or blood from the patient were followed up with daily temperature and symptom monitoring for 14 days after contact. Efforts were also made to inform other potential contacts including passengers on the flight from Kabul to Dubai. Nevertheless, no secondary transmission from the original case has been observed as of 28 November.

\section{Discussion}

While CCHF is an uncommon disease, importations from countries where the virus is endemic and where European countries have links such as Afghanistan, Pakistan and India; are possible. CCHF poses important challenges to patient management and infection control; however, the attentiveness of medical staff, laboratory workers and public health officials to global virological and zoonotic developments can ultimately help deal with such problems.

Rapid and sensitive detection of CCHF virus using a PCR approach offers an important advantage to infection control and patient management. This is significant during the early stages of disease when high titres of infectious virus are present in blood, bodily secretions and fluids such as vomit [7].

The estimated viral load in the sample collected approximately on the fifth day of disease, of $6.0 \times 10^{7}$ copies per $\mathrm{mL}$ seems to be consistent with other reports of poor outcome [8]. However, care should be made in drawing comparisons with other studies as only one sample was obtained from this case and it was not possible to retrieve immunological data on the IgM and IgG responses.

Incidents of nosocomial transmission are common in the absence of a clear CCHF diagnosis, and direct contact with bodily secretions $[9,10]$, including infection via small-particle aerosol or droplets through the eye mucosa have been reported [11]. In addition, interventions to gastrointestinal bleeding, and emergency operations on patients who have yet to be diagnosed with CCHF offer the most hazardous route for acquiring the disease in a hospital setting [12-14]. Rapid diagnosis of CCHF in this particular case and similar situations is therefore important in preventing nosocomial transmission. CCHF viruses are highly diverse and it is important that assays based on rapid technology such as PCR are able to detect all possible CCHF genetic variations. To achieve this it has been fundamental to our work on CCHF to maintain ongoing research programmes that are linked to virus endemic areas of the world such as Tajikistan and Pakistan $[15,16]$. As part of these programmes, our assay has been tested and validated with circulating strains of virus. In particular collaborative work in Tajikistan and Pakistan has enabled the assay to be fine-tuned, so that there is confidence in the ability to detect strains from the region.

Interestingly, when compared to other CCHF virus sequences, the SCT ex Afghanistan $\mathrm{S}$ sequence obtained from the patient in this report, shows strong similarity to CCHF viruses from the Middle East which cluster together in the Asia 1 group (Figure). Such information alludes to the source of virus and it is noteworthy that the patient is believed to have acquired the virus, through direct contact with infected blood or other tissues, during the slaughtering of an animal while in the village of Aibak in Samangan Province, approximately $250 \mathrm{~km}$ northwest of Kabul.

\section{Acknowledgement}

This report contains work commissioned by the National Institute for Health Research (NIHR). The views expressed are those of the authors and not necessarily those of the National Health Service (NHS), the National Institute for Health Research or the Department of Health. The authors would also like to acknowledge the assistance of the UK Global Partnership Biological Engagement Programme in funding development programmes underpinning this capability.

\section{References}

1. Atkinson B, Chamberlain J, Logue CH, Cook N, Bruce C, Dowall $\mathrm{SD}$, et al. Development of a real-time rt-PCR assay for the detection of crimean-congo hemorrhagic Fever virus. Vector Borne Zoonotic Dis. 2012;12(9):786-93.

2. Aradaib IE, Erickson BR, Mustafa ME, Khristova ML, Saeed NS, Elageb RM, et al. Nosocomial outbreak of Crimean-Congo hemorrhagic fever, Sudan. Emerg Infect Dis. 2010;16(5):837-9.

3. Mardani M, Keshtkar-Jahromi M, Ataie B, Adibi P. CrimeanCongo hemorrhagic fever virus as a nosocomial pathogen in Iran. Am J Trop Med Hyg. 2009;81(4):675-8.

4. Nabeth P, Cheikh DO, Lo B, Faye O, Vall IO, Niang M, et al. Crimean-Congo hemorrhagic fever, Mauritania. Emerg Infect Dis. 2004;10(12):2143-9.

5. Department of Health (DH). Management of Hazard Group 4 viral haemorrhagic fevers and similar human infectious diseases of high consequence. England: DH. [Accessed 14 Nov 2012]. Available from: http://webarchive.nationalarchives.gov. uk/+/www.dh.gov.uk/ab/ACDP/DH_130727

6. Royal Air Force (RAF) Air Transport Isolator. United Kingdom: RAF. [Accessed 14 Nov 2012]. Available from: http://www.raf. mod.uk/PMRAFNS/organisation/airtransportisolator.cfm

7. Whitehouse CA. Crimean-Congo hemorrhagic fever. Antiviral Res. 2004;64:145-160.

8. Duh D, Saksida A, Petrovec M, Ahmeti S, Dedushai I, Panning M, et al. Viral Load as a Predictor of CrimeanCongo Hemorrhagic Fever Outcome. Emerg Infect Dis. 2007;13(11):1769-71.

9. Drosten C, Kummerer BM, Schmitz H, Gunther S. Molecular diagnostics of viral hemorrhagic fevers. Antiviral Res. 2003;57(1-2):61-87.

10. Ergönül O. Crimean-Congo haemorrhagic fever. Lancet Infect Dis. 2006;6:203-214.

11. Hoogstraal, H. The epidemiology of tick-borne Crimean-Congo hemorrhagic fever in Asia, Europe, and Africa. J Med Entomol. 1979;15(4):307-417.

12. Burney MI, Ghafoor A, Saleen M, Webb PA, Casals J. Nosocomial outbreak of viral hemorrhagic fever caused by Crimean hemorrhagic fever-Congo virus in Pakistan, January 1976.Am J Trop Med Hyg. 1980;29(5):941-7. 
13. Suleiman MN, Muscat-Baron JM, Harries JR, Satti AG, Platt GS, Bowen ET, et al. Congo/Crimean haemorrhagic fever in Dubai. An outbreak at the Rashid Hospital. Lancet. 1980;2(8201):939-1.

14. Altaf A, Luby S, Ahmed AJ, Zaidi N, Khan AJ, Mirza S, et al. Outbreak of Crimean-Congo haemorrhagic fever in Quetta, Pakistan: contact tracing and risk assessment. Trop Med Int Health. 1998;3(11):878-82.

15. Hasan Z, Mahmood F, Jamil B, Atkinson B, Mohammed $M$, Samreen A, et al. Crimean-Congo Hemorrhagic Fever Nosocomial Infection in an Immunosuppressed Patient, Pakistan: Case Report and Virological Investigation. J Med Virol. Forthcoming 2012.

16. Tishkova FH, Belobrova EA, Valikhodzhaeva M, Atkinson B, Hewson R, Mullojonova M. Crimean-Congo hemorrhagic Fever in Tajikistan. Vector Borne Zoonotic Dis. 2012;12(9):722-6. 